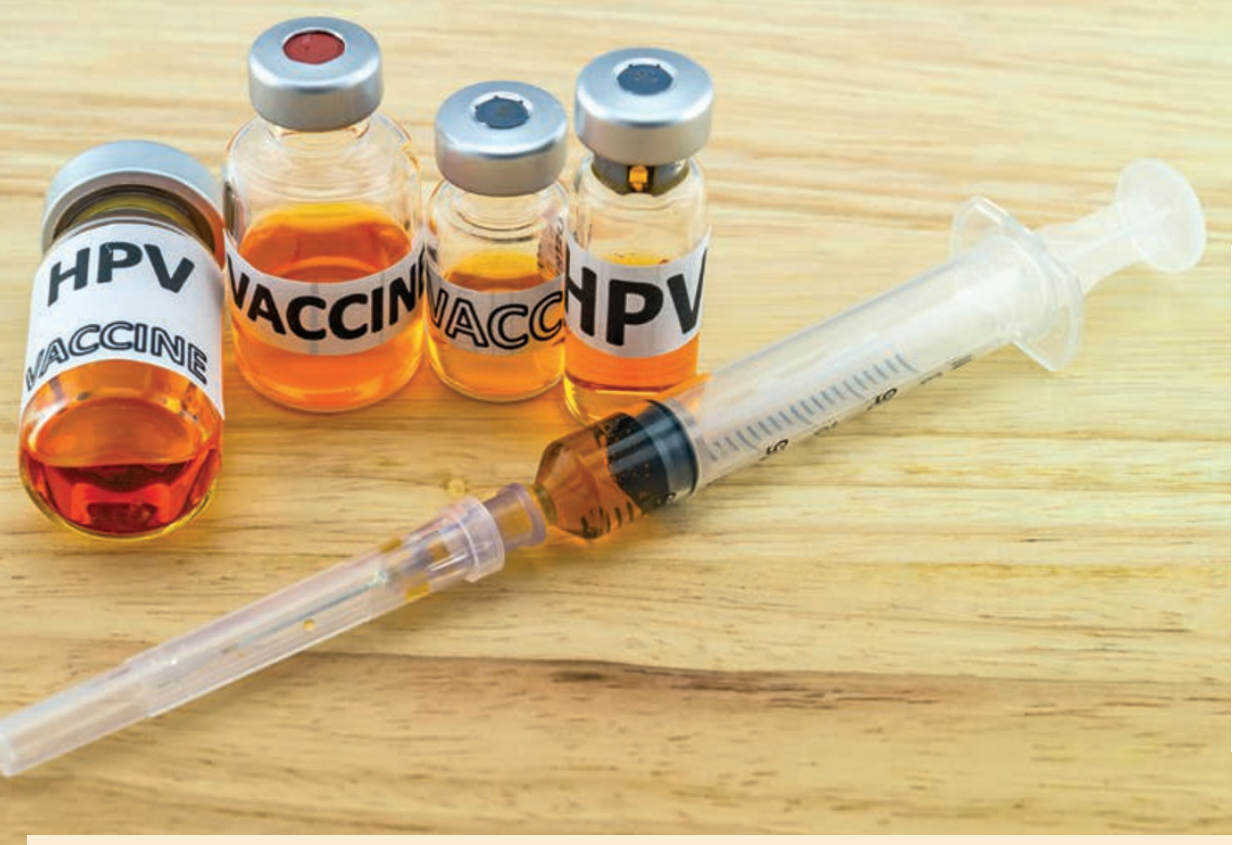

\title{
OUTCRY OVER DECISION ON HPV VACCINATION
}

7 here has been wide condemnation of the news that the Joint Committee on Vaccination and Immunisation (JCVI) has decided not to recommend an extension of the Human Papilloma Virus (HPV) vaccination to school age boys.

HPV has been linked to one in 20 cases of cancer in the UK. Health campaigners have called for a gender-neutral approach to vaccination, which would ensure 400,000 school-age boys are not left at risk.

Up to $80 \%$ of sexually active people will be infected by HPV at some point in their lives. Five percent of all cancers are caused by HPV and some of these, notably oral cancers, are now rising sharply in incidence. HPV-related cancers such as anal cancer are also among the hardest to diagnose and treat.

A recent poll published by the campaign coalition HPV Action for World Immunisation Week (24-28 April) showed that $97 \%$ of dentists backed expansion of the programme, with the same proportion saying if they had a son they would want them to receive the vaccination.

This initial recommendation by JCVI will now be subject to a public consultation, and the British Dental Association (BDA) will make representations to the Committee urging them to reconsider the evidence before they make their final decision in October. BDA Chair Mick Armstrong said: 'JCVI's unwillingness to expand the vaccination programme to boys is frankly indefensible. The state has a responsibility to offer all our children the best possible defence. Dentists are on the front line in the battle against oral cancer. Ministers can choose to sit this one out, or show they really believe in prevention'.

Dr Mick Horton, Dean of FGDP(UK), said: 'It is astonishing that the Government's vaccination advisory committee is planning to recommend that men are not given a level of immunity which the NHS already provides to women, and from a vaccine which it acknowledges is just as effective for men. The JCVI's position will cost lives, and as it consults it should start listening to the dentists and doctors who see the devastation that HPV-related cancers wreak on patients and their families'.

The British Association of Dental Nurses (BADN) also condemned the decision and President Jane Dalgarno said: 'BADN supports the HPV Action campaign and calls upon its members to lobby their MPs to make them aware of the seriousness of this matter'.

\section{Dral Health Comference to be held in Harrogate}

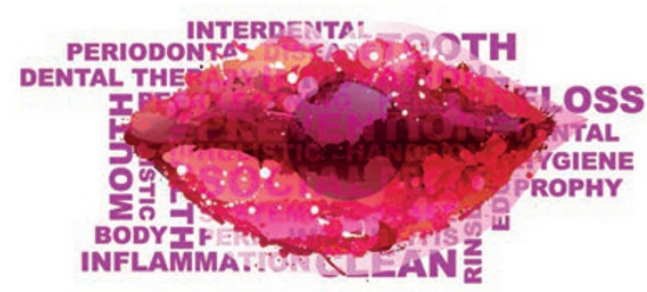

This year's Oral Health Conference and Exhibition will be held on 3-4 November 2017 at Harrogate Convention Centre. The event is the highlight in the British Society of Dental Hygiene and Therapy's (BSDHT's) calendar.

Offering first-class clinical education, hours of CPD and an opportunity to network with colleagues, experts and industry, there will be something for all dental hygienists and dental therapists to enjoy.

The extensive programme will be presented by speakers at the cuttingedge of the profession. Whether you're looking for regulation updates, advice on clinical procedures, ideas to help boost patient communication or inspiration for career development, the BSDHT has you covered.

The event will also once again host the Annual Poster Competition, sponsored by Waterpik International, Inc. This is a great opportunity for you to share your passion, commitment and research with the wider profession, plus, you'll be in with a chance to win a fantastic prize.

Entitled 'More to the Mouth', the Oral Health Conference and Exhibition is the ideal platform for modern dental hygienists and dental therapists to get up-to-date with the very latest in field.

For more information and to book, visit www.bsdht.org.uk/oral-healthconference-and-exhibition. 